\title{
Assessment of seismic responses toward multi-story buildings of steel special moment resisting frame by considering the setback irregularities
}

\author{
Ridho Aidil Fitrah ${ }^{1 *}$, Masrilayanti Masrilayanti ${ }^{1}$, Gita Zakiah Putri ${ }^{2}$, and Zev Al Jauhari ${ }^{3}$ \\ ${ }^{1}$ Civil Engineering Department, Andalas University, , 25163 Limau Manis, West Sumatera, Indonesia \\ ${ }^{2}$ Civil Engineering Department, Astra Manufacturing Polytechnic, 14330 Sunter, Jakarta, Indonesia \\ ${ }^{3}$ Civil Engineering Department, Bengkalis State Polytechnic, 28711 Sungai Alam, Riau, Indonesia
}

\begin{abstract}
Setback irregularities are considered where discontinuity between adjacent stories is excessive. This irregularity caused the probability of high damage at structures subjected to strong earthquake motion. For this purpose, this study was conducted by modeling the steel special moment frame (SMF) structures using a finite element calculation program with nonlinear static analysis compared to Padang city's response spectrum. The buildings are also modeled with two types of setbacks: single and multiple setbacks. The results of this paper are discussed including the explanation of many parameters that relate to elastic and inelastic seismic responses of steel special moment frame (SMF). Based on the results, the setback irregularities, both single and multiple setbacks, the inelastic seismic responses are adequately sufficient to SNI 17262019 regarding drift limit. The other seismic responses are also discussed in terms of fundamental periods, inter-story drifts, story stiffness, and base shear. Referred to Indonesian Seismic Provision, SNI 1726 2019, it is found that single setback building has more adequate than multiple setbacks in terms of seismic responses. Then, the seismic assessments between these setbacks are explained to address the recommendations about future prevention toward damages and failures in steel buildings.
\end{abstract}

\section{Introduction}

Vertical irregularities are found in some constructions such as multi-story or high-rise buildings and industrial plants. It is considered to give better serviceability and also architectural demand. Mass, stiffness, and strength are the main parameters to determine that vertical irregularities exist in multi-story buildings. The existence of the setback irregularities is determined as the sudden change of mass, stiffness, and strength due to the discontinuity of the adjacent story. According to the seismic provision in Indonesia, SNI 1729:2019, The setback irregularities are determined as a comparison the length of bays between adjacent stories is higher than $130 \%$.

Throughout the year, most of the researches in reinforced concrete and steel buildings considering setback irregularities has stated the seismic responses of these buildings. It was found that there are several undesirable parameters because they generated a higher inter-story drift along with building height. Humar and Wright [1] concluded the setback would cause significant inelastic deformation if the numbers of bays in some stories were smaller than its lower stories. Duan and
Chandler [2] stated that the structural members located near the setback would generate severe damage, as a result, the proper and stronger design should be applied specifically to those members. Chen et. al [3] considered controlling structural responses while the larger setbacks in stories simultaneously affected local vibration. Moreover, research from Karavasilis et.al [4] revealed the parameters that need to be concerned in buildings with setbacks such as the number of stories, geometrical irregularity, and beam-column strength ratio.

On the other hand, researchers also found that there are no significant effects regarding seismic responses. Piluso [5] stated that as long as the structures are designed to have a global collapse mechanism, the setbacks irregularities do not take place as the main cause for worsening the seismic responses. Based on practical evidence, Kappos and Scott [6] also concluded that there are no significant results regarding local failures in structural members near seatbacks while Tena-Colunga [7] also analyzed that plastic deformations did not find as the cause of the setbacks irregularity's existence. Romao et.al [8] stated that the seismic responses of reinforced concrete buildings with setbacks irregularities were adequate as well as regular frame according to the

*Corresponding author: ridho@eng.unand.ac.id 
Eurocode provision. Therefore, there is still a contrary issue that needs further studies to acquire the proper explanation in terms of seismic responses due to setbacks irregularities. Also, it needs further observation while seismic accelerations and intensity always increase throughout the year depending on the movement of faults around the world. It also affects the development of the design to prevent excessive seismic response toward buildings.

In Indonesia, seismic acceleration in every province had risen higher based on provision SNI 1726:2019. More restrictions are applied concerning the chosen analysis for designing structural members either steel or reinforced concrete, specifically in high-intensity earthquake regions. The studies have been done in several cases to know how it can affect seismic responses and building design $[9,10]$. It was found that many indicators are playing the role to make structural members get attention to adjust sufficient structural responses for instance response modification factors, and amplification factors which are determined to acquire actual elastic and inelastic seismic responses and level of building's performance. Furthermore, both horizontal and vertical irregularities in buildings are also accounted to give restrictions in analysis and design [11,12]. Then, this study is conducted to obtain seismic responses due to setback irregularities in the multi-story building of steel special moment-resisting frames. The results of seismic response discussed in this paper for getting assessment about sufficiency toward SNI 1726:2019 due to various models of setback irregularities, single and multiple setbacks.

\section{Methodology}

\subsection{Building Modelling}

To research the seismic responses of special steel moment-resisting frame buildings, three various steel buildings were modeled in finite element software with 6 stories and $24 \mathrm{~m}$ total height above ground level. Buildings had a regular plan view with a $6.0 \mathrm{~m}$ bay span. To get a seismic responses comparison, the regular building (SMRF-Reg) without setback was modeled in Fig 1. The setback irregularities were applied to be sufficiently categorized as vertical irregularities just as mentioned in SNI 1726:2019 [13]. Single and multiple setbacks were shown in Fig 1 (b) and (c). Fig 1(b) was a single setback building that has $300 \%$ setbacks between story 3 and story 4 (SMRF-Set1). Fig 1(c) was a multiple setback building that has $150 \%$ setback between story 2 and story 3 and $200 \%$ setback between story 3 and story 4 (SMRF-Set2).

Every structural member in special steel momentresisting frame buildings was sufficiently designed based on AISC 360-16 (SNI 1729:2020) by using its specific factors such as modification response $(\mathrm{R})$ is 8 , amplification factor $\left(\mathrm{C}_{\mathrm{d}}\right)$ is 5.5 , and importance factor (I) is 1.5 [14]. Then, the buildings were also able to withstand toward dead load and live load respectively $2.5 \mathrm{kN} / \mathrm{m}^{2}$ and $3 \mathrm{kN} / \mathrm{m}^{2}$.

\subsection{Seismic Analysis}

Seismic analysis toward these buildings was conducted by generating a response spectrum of Padang City, West Sumatera, which included a dynamic analysis, with site class D (SD). According to SNI 1726:2019, by obtaining spectral acceleration at short period $\left(\mathrm{SD}_{\mathrm{s}}\right)$ and one second period $\left(\mathrm{SD}_{1}\right)$ also the importance factor (I), these buildings were categorized as seismic design category of $\mathrm{D}$ where the special steel moment-resisting frame design is applied as the designed models. Furthermore, the response spectrum of Padang City which is used in this analysis already shown in Fig.2.

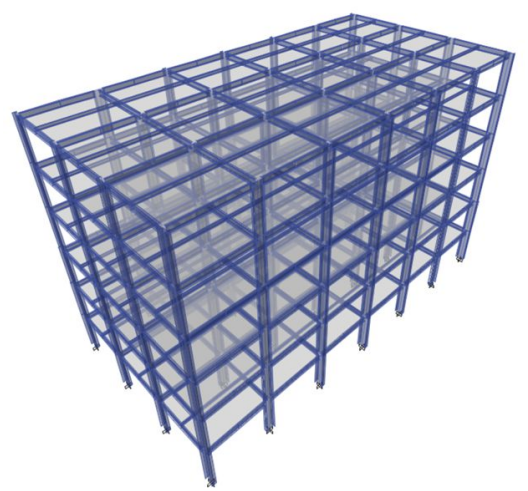

(a)

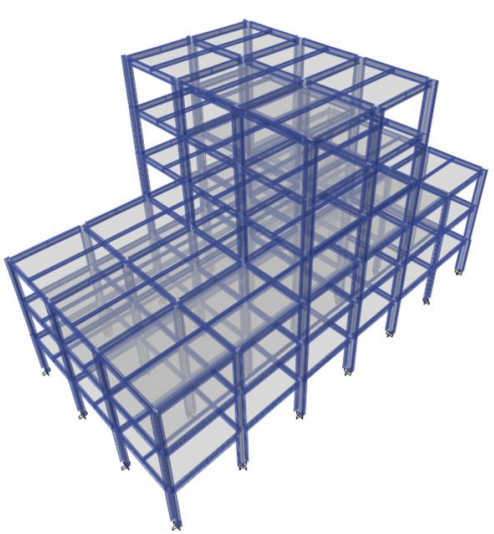

(b)

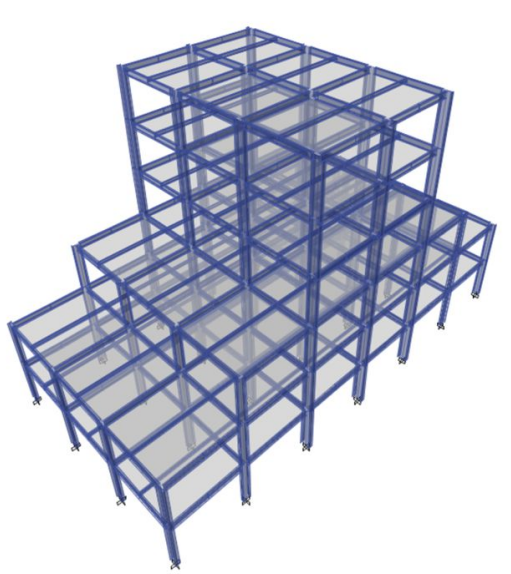

(c)

Fig. 1. Building models (a) SMRF-Reg (b) SMRF-Set1 (c) SMRF-Set2 


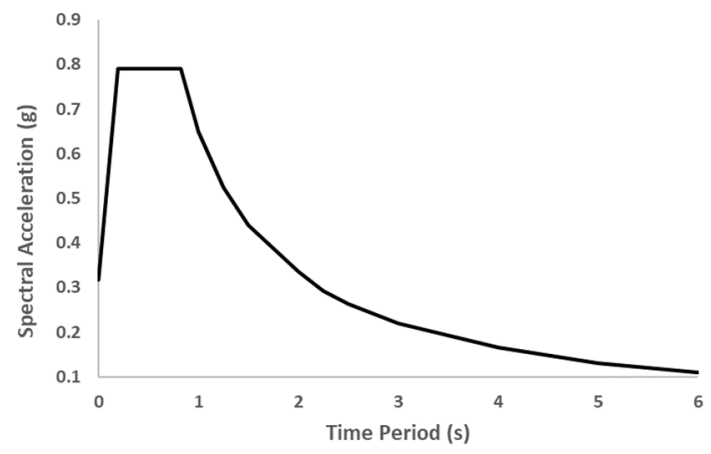

Fig. 2. Response Spectrum of Padang City (SD)

According to SNI 1726:2019, The base shears both static and dynamic analysis must have a similar comparison that meets the value $100 \%$, which means the scale factor is needed in analysis to get the representative results toward elastic seismic response during the earthquake. The displacement and inter-story drift either $\mathrm{X}$ or $\mathrm{Y}$ direction were evaluated and discussed regarding the sufficiency toward SNI 1726:2019 drift limitation.

\section{Results and Discussions}

\subsection{Fundamental Period}

The fundamental period is one of the dynamic properties to determine how seismic force will impact building responses. Furthermore, the fundamental period is influenced by mass and stiffness which means structural configuration takes part in determining this value. The longer the fundamental period of the building, the more flexible structure will deform. It affects the value of base shear and structure's displacements.

Table 1 shows the comparison between the calculated period of the first mode through computer analysis and empirical fundamental periods according to SNI 1726:2019 in three building models. It shows that the SMRF-Reg had the biggest fundamental period among other models (SMRF-Set1 and SMRF-Set2) which these models categorized as having setback irregularities. It could be explained that floor plans were decreased due to setback irregularities while the story mass similarly decreased. There are also no torsional issues such as eccentricity between the center of rigidity and center of mass.

Table 1. Comparison of Buildings' Fundamental Period

\begin{tabular}{|c|c|c|c|}
\hline Structure & $\begin{array}{l}\text { Coeffi- } \\
\text { cient } \\
\left(C_{u}\right)\end{array}$ & $\begin{array}{c}\text { Empirical } \\
\text { Fundamenta } \\
\text { I Period }\left(T_{a}\right) \\
(s) \\
\end{array}$ & $\begin{array}{l}\text { First Mode } \\
\left.\text { Period ( } T_{1}\right) \\
\quad(s)\end{array}$ \\
\hline SMRF-Reg & \multirow{3}{*}{1.4} & \multirow{3}{*}{$0.0724 \mathrm{~h}_{\mathrm{n}}{ }^{0.8}$} & 1.781 \\
\hline SMRF-Set1 & & & 1.426 \\
\hline SMRF-Set2 & & & 1.478 \\
\hline
\end{tabular}

$\mathrm{h}_{\mathrm{n}}$ : Total of Building Height
However, as long as the center of mass and rigidity between adjacent stories tend to have a similar location, the setback irregularities would not take a significant effect on the structural modes. To emphasize the explanation, as long as the structural members were designed adequately, the setback irregularities also would not have a possibility to experience torsional either in $\mathrm{X}$ or Y direction.

\subsection{Story Stiffness}

To obtain a better comprehension of the seismic response, the story stiffness is also the parameter to determine how the flexibility of the structure. As mentioned in the previous discussion, story stiffness will determine how significant the deformation of structures is.

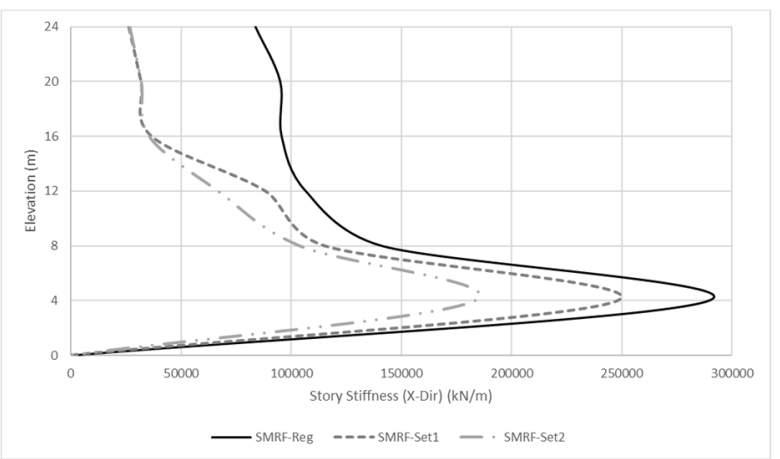

(a)

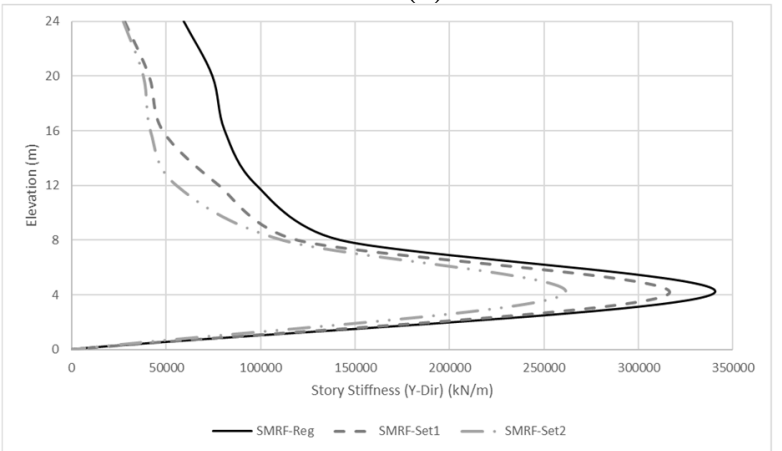

(b)

Fig. 3. Story Stiffness of Steel Buildings (a) X-direction (b) Ydirection

According to Fig.3, the graph of story stiffness of three steel structural models, either X or Y- direction, the SMRF-Reg had the largest story stiffness compared to SMRF-Set1 and SMRF-Set2. However, single and multiple setbacks were identified exist in X-direction. Then, it could be explained that the story stiffness of a single setback (SMRF-Set1) was slightly higher than the multiple setbacks (SMRF-Set2) even though the percentage of a single setback was about twice higher than multiple setbacks. Moreover, the discontinuity in the certain plane i.e setback irregularities would affect the structure to become more flexible so that the higher structural deformation in a certain direction must be larger than the regular building. 


\subsection{Base Shear}

The influence of setback irregularities on special steel moment-resisting frame (SMRF) buildings is observed according to base shear. This force is determined by the story stiffness and fundamental period. Fig. 4 shows that the SMRF-Reg has a $60 \%-75 \%$ larger base shear force than the other setback structures (SMRF-Set1 and SMRF Set-2) either in X or Y direction. Therefore, the setback irregularities caused significant effects regarding base shear force. However, when it is compared to setback structures, it can be seen that multiple setbacks structure has slightly different base shear force than the single setback structure. Then, it can be explained that the multiple setbacks structure (SMRF-Set2) is more flexible than the single setback structure (SMRF-Set1).
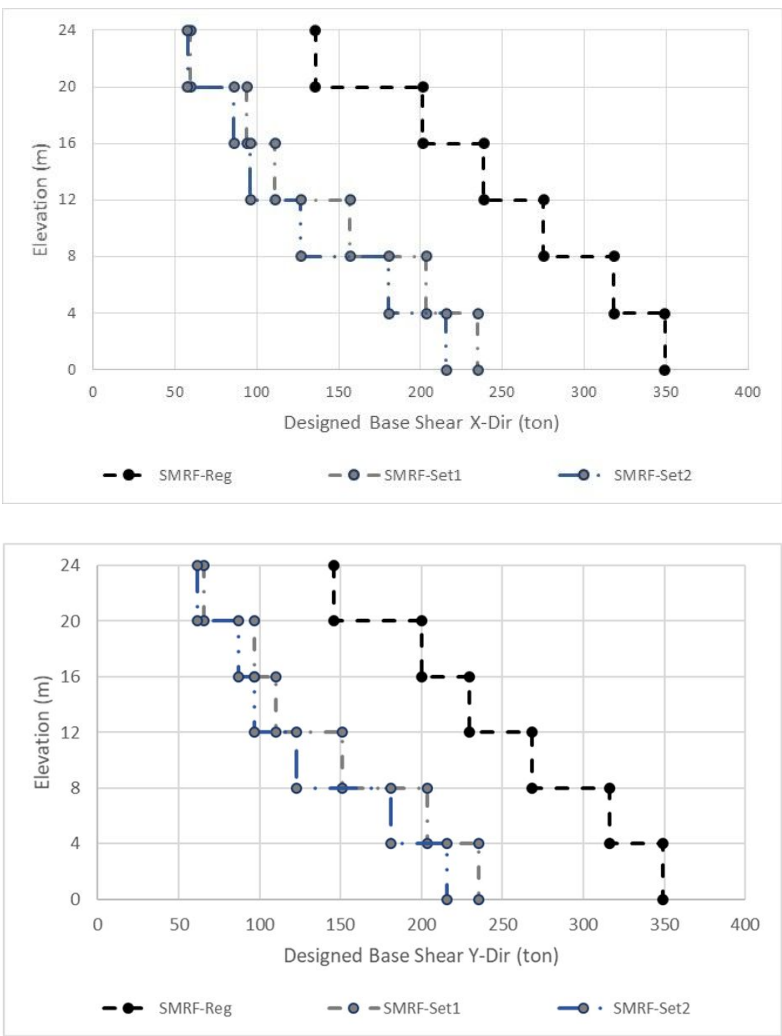

Fig. 4. Base Shear of Steel Buildings (a) X-direction (b) Ydirection

\subsection{Story Displacement}

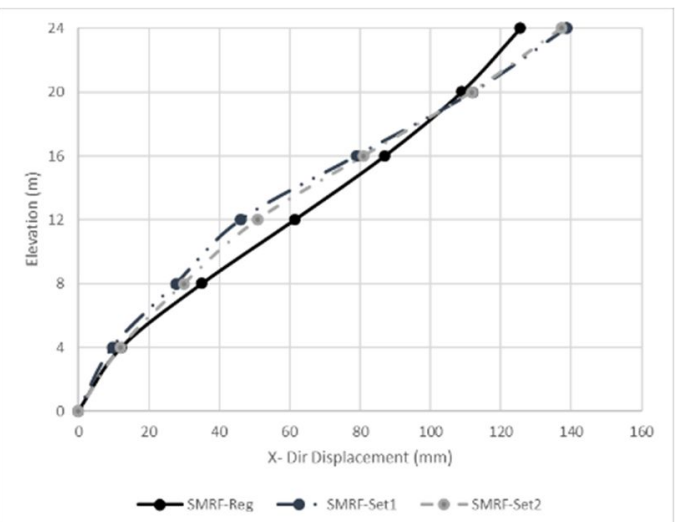

a)

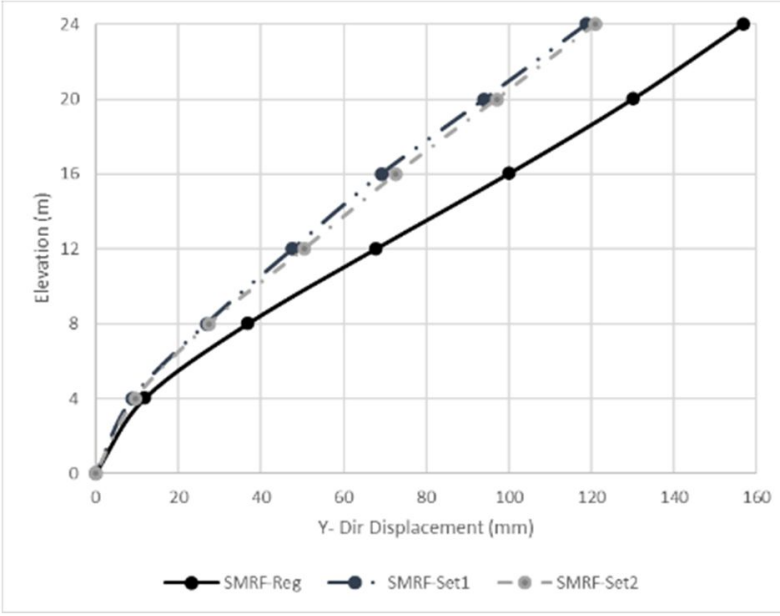

(b)

Fig. 5. Story displacement of Steel Buildings (a) X-direction (b) Y-direction

To study how the setback irregularities would affect inelastic seismic response due to seismic excitation. Then, the story displacement is discussed in Fig. 5 which represents the comparison between the story displacement in $\mathrm{X}$ and $\mathrm{Y}$ direction. The graph shows that the story displacement of regular structure (SMRF-Reg) is dominantly higher than the setback structures about 5\%$25 \%$ in $\mathrm{X}$-direction and $11 \%-33 \%$ in $\mathrm{Y}$-direction. It can be annotated that the seismic weight of this building is also higher than setback structures. Therefore, the P-delta would be highly accounted to this regular frame rather than the setbacks structures.

Either in $\mathrm{X}$ and $\mathrm{Y}$ direction, the story displacements of setbacks structure (SMRF-Set1 and SMRF-Set2) tend to have similar values. Therefore, single and multiple setbacks did not influence story displacement. However, to assess the sufficiency of the elastic seismic response toward Indonesia's seismic provision SNI 1726:2019, The advanced calculation about inter-story drift is discussed below.

\subsection{Inter-Story Drift}

The inter-story drift is defined as the relative translational displacement between two consecutive floors. SNI 1726:2019 stated that the limitation of inter-story drift must be determined to prevent excessive inelastic responses. To obtain the comprehension of the influence of the setback irregularities regarding inter-story drift, Fig. 6 shows the comparison of them in X and Y-direction. Both directions seem an adequate value for the inter-story drift. Generally, the setback irregularities did not have a significant influence. However, the buildings were designed to accommodate the load combination in serviceability and ultimate condition. This emphasizes that as long as the steel design is sufficient, so there are no issues regarding the excessive inelastic seismic responses upon the drift limit.

On the other hand, in the X-direction where the setback appeared, the inter-story drift in setback structures 
tends to have a bigger value rather than regular structures. Though the value is adequately sufficient to drift limit, the pattern of inter-story in setback structures (SMRF-Set1 and SMRF-Set2) did not follow a conservative pattern where the inter-story drift must be smaller while the story is increasing. For example, from story-3 to story-4 (elevation $12 \mathrm{~m}$ to $16 \mathrm{~m}$ ), the inter-story drift in SMRFSet1 was significantly changing about $78 \%$ while SMRSet 2 was significantly changing about $44 \%$.

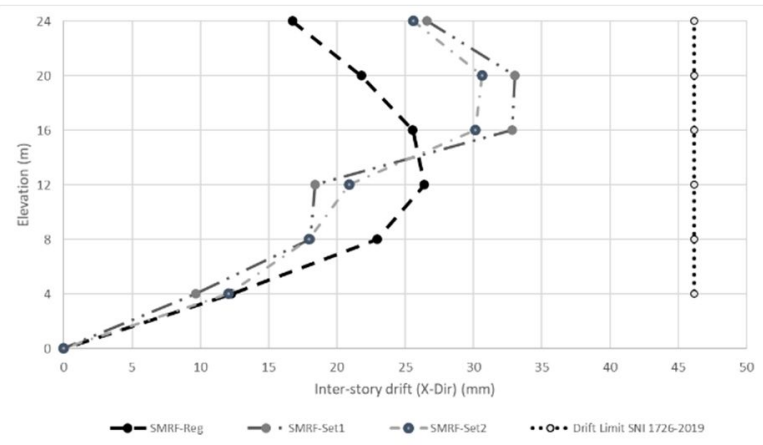

(a)

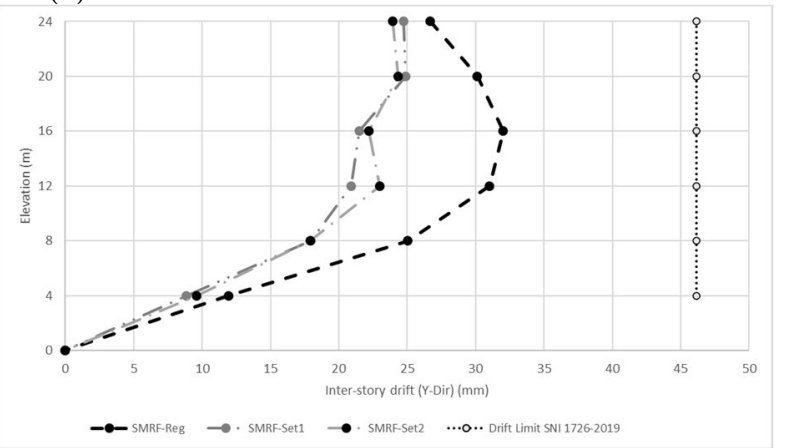

(b)

Fig. 6. Inter-story Drift of Steel Buildings (a) X-direction (b) Y-direction

The assessment can be carried out regarding the significant change between the adjacent stories. It will lead the structures would have partly plastic deformation and soft-story mechanism. Then, for the future prevention of failure in certain floors, several options can be applied to decrease the inter-story drift.

\section{Conclusions}

This research aimed to assess the inelastic seismic responses toward the multi-story buildings of special steel moment-resisting frames due to the existence of setback irregularities according to SNI 1726:2019. This assessment is conducted because of the increment of seismic acceleration in Padang City. To obtain the representative comparisons, the regular building was also modeled. Furthermore, these buildings were also designed to accommodate the service and ultimate loads, including the seismic load. Analysis and assessment were conducted in fundamental periods, the base shear, the story stiffness, and inter-story drift.

So, the conclusions of the assessment due to setback irregularities can be listed as follows:
1. The setback irregularities did not influence the fundamental periods and mode shapes, as long as the structural members were properly designed. Then, mode shapes 1 and 2 were translational in both $\mathrm{X}$ and Y-direction.

2. Story stiffness and base shear are the parameters that are affected due to the setback irregularities. It is found that these values were significantly smaller than a regular building. Multiple setbacks structure is found to be more flexible rather than single setback structure. Then, it influences the lateral deformation in a building.

3. Based on the assessment in the inter-story drift of steel buildings seems to be adequately sufficient to SNI 1726:2019. However, due to the setback irregularities, the pattern of the inter-story drift did not follow a conservative pattern. The bigger percentage of setbacks then affects the significant change between adjacent stories.

4. To prevent failure such as soft-story or partly plastic deformation because of the significant change of inter-story drift between the adjacent stories, the future design must be considered to increase the story stiffness where setbacks appeared.

\section{References}

1. J.L Humar, E.W Wright, Earthquake Engineering \& Structural Dynamics, 5 (1977).

2. X.N Duan, A.M Chandler, Earthquake Engineering and Structural Dynamics, 24, 761-77 (1995)

3. C Chen, N.T.K Lam, P Mendis, The bifurcation behavior of vertically irregular buildings in low seismicity regions. In Proceeding: 12th world conference on earthquake engineering. (2000).

4. T. L.Karavasilis, N. Bazeos, and D. E. Beskos, J. of Constructional Steel Research, 64 (6) (2008)

5. F. Mazzolani, V. Piluso, Theory, and design of seismic resistant steel frames. London, New York: FN \& SPON an Imprint of Chapman \& Hall (2012)

6. AJ Kappos, SG Scott, Seismic assessment of an $R / C$ building with setbacks using nonlinear static and dynamic analysis procedures, In Booth, editor. Seismic design practice into the next century. (1998)

7. A Tena-Colunga, Evaluation of the seismic response of slender, setback $R C$ moment-resisting frame buildings designed according to the seismic guidelines of a modern seismic code. In: 13th world conference on earthquake engineering, (2004)

8. X Romão, A Costa, R Delgado, Seismic behavior of reinforced concrete frames with setbacks. In: 13th world conference on earthquake engineering, (2004)

9. Z.A Jauhari, F. Ananda, R.A Fitrah, Comparison of the design acceleration response spectra in Riau Province between SNI 1726: 2019 and SNI 1726: 2012 methods. In Proceeding IOP Conference Series: Earth and Environmental Science, (2021)

10. R.A Fitrah, A.P Melinda, Rang Teknik Journal, 2 (2018) 
11. R.A Fitrah, D.I Mazni, W Pratiwi, Z.A Jauhari, Seismic assessment of irregularities in steel special moment resisting frame with asymmetric-plan building (case study: Gedung D-Universitas Dharma Andalas). In Proceeding IOP Conference Series: Earth and Environmental Science, (202

12. B. Budiono, E.B Wicaksono, Jurnal Teknik Sipil, 113-126 (2016)
13. National Standardization Agency, SNI 1726-2019, Design Method of Earthquake Resistance for Buildings and Other Structures, BSN, Jakarta (2019).

14. National Standardization Agency, SNI 1729: 2020, Requirements of Steel Structure for Building, BSN, Jakarta (2020) 